\title{
Improved interfacial transition zone between aggregate-cementitious matrix by addition sugarcane industrial ash
}

\author{
João Adriano Rossignolo a, *, Michelle Santos Rodrigues ${ }^{a}$, Moises Frias ${ }^{\text {b }}$, \\ Sérgio Francisco Santos ${ }^{c}$, Holmer Savastano Junior ${ }^{a}$ \\ a University of São Paulo (USP), Department of Biosystems Engineering, Pirassununga, Brazil \\ ${ }^{\mathrm{b}}$ Eduardo Torroja Institute for Construction Science (IETCC-CSIC), Madrid, Spain \\ c São Paulo State University (UNESP), School of Engineering, Department of Materials and Technology, Guaratingueta, Brazil
}

\section{A R T I C L E I N F O}

\section{Article history:}

Received 6 June 2016

Received in revised form

19 December 2016

Accepted 16 March 2017

Available online 18 March 2017

\section{Keywords:}

Interfacial transition zone (ITZ)

Nanoindentation

Sugarcane industrial ash

Microstructure

\begin{abstract}
A B S T R A C T
The aim of this study was to evaluate the influence of sugarcane industrial ash (SCIA) on mechanical properties of interfacial transition zone (ITZ) between aggregates and cementitious matrix by nanoindentation technical analysis. The sugarcane biomass (agroindustrial by-product) was used for generation of electricity by burning in a cogeneration power system. The results of nanoindentation analyses showed that the ITZ thickness varied significantly with the water/binder ratio. Each formulation used different water and binder ratio, with the inclusion of $20 \%$ silica fume (SF) or SCIA. In fact, the mineral additions caused a reduction of the thickness of the matrix-aggregate ITZ, and consequently increased the values of the indentation modulus and hardness in relation to aggregate-matrix interface of the reference concrete.
\end{abstract}

@ 2017 Elsevier Ltd. All rights reserved.

\section{Introduction}

Brazil is the largest producer of sugarcane in the world, with a total of 632 mil tons/year (2015/2016). It is known that approximately $28 \%$ of the sugarcane production is bagasse i. e. for each tonne of processed sugarcane; there are about $270 \mathrm{~kg}$ of bagasse and straw, resulting in a significant amount of bagasse available for energy use in the coming years. This bagasse is composed of: cellulose (43 wt\%), hemicellulose (26 wt\%), lignin (24 wt\%) and ashes (7 wt\%) [1].

Currently, sugarcane bagasse has been considered mainly agroindustrial by-products, because this biomass is burned to produce electricity in a cogeneration power system at the sugar and ethanol industry [2,3]. The straw became another solid by-product with sugarcane mechanized harvesting. About $14 \%-18 \%$ of straw by tons of sugarcane produced [4]. The straw is composed of: water (15 wt\%), ash (2 wt\%), and biomass fibers (83 wt\%) [5]. Several applications for this waste have been studied, such as the

\footnotetext{
* Corresponding author. Departamento de Engenharia de Biossistemas - USP. Av. Duque de Caxias Norte, 225.CEP, 13635-900, Pirassununga, SP, Brazil.

E-mail addresses: rossignolo@usp.br (J.A. Rossignolo), michatcsr@yahoo.com.br (M.S. Rodrigues), mfrias@ietcc.csic.es (M. Frias), sfsantos@feg.unesp.br (S.F. Santos), holmersj@usp.br (H.S. Junior).
}

generation of cellulosic ethanol second-generation [6-8]. Furthermore, the straw also has been used as biomass to burn in a cogeneration power system. Therefore, the Brazilian sugarcane agroindustry generates a lot of solid by-products.

In addition, researchers have conducted studies using the sugarcane straw ash (SCSA) and sugarcane bagasse ash (SCBA) as mineral addition in cement matrix [9-12].

The use of these ashes can modify the particle size distribution of the mix designs, concrete rheology, increase pozzolanic activity and mechanical, chemical and physical properties of the cementitious matrix.

Cordeiro et al. (2009) [13] observed that blended cement with SCBA and rice husk ash (RHA) can interfere in the concrete rheological behavior and increase the resistance to penetration of chloride ions. This change was consequence of the pozzolanic activity of both ashes and the refinement in the pore size distribution in relation to the reference concretes [13]. Furthermore, SCSA for its greater reactivity with Portland cement can increase the mechanical strength of mortars [9], and can also increase the modulus of rupture and tenacity of fiber cement composite because the SCSA collaborated to protect the lignocellulosic fibers reducing alkalinity and improvement the interface with cementitious matrix. In this way, the pullout and bridging mechanisms are more efficient in the fracture process [14]. 
In a previous work, researchers conducted the blended cement mixtures elaborated with SCBA and fly ash (FA), and they concluded that the shape and size distribution of the particles of the SCBA produced a pseudoplastic behavior (non-Newtonian behavior when the viscosity changes when the shear rate changes i.e. Higher shear rates $=$ lower viscosity) and workable pastes and mortars i. e. a better rheological behavior than mixes without SCBA. The use of $20 \%$ of FA combined with $10 \%$ or $20 \%$ of SCBA was beneficial to produce lower yield stresses related to rheological behavior than those presented in a binary system - Portland cement with SF or Portland cement with SCBA [14].

Thus, the cement matrices can incorporate one or various mineral addition in order to manufacture binary, ternary or quaternary blended cements [15-17]. However, there are some challenges regarding the use of mineral addition in blended systems, as examples: most amount of water required, because the water normalizes the rheological behavior of a fresh cement paste that depends on particle size distribution, morphology of the particles, specific surface area, zeta potential among other characteristics of a mineral addition, and also, in some cases, such as pulverized fuel ash and metakaolin, the generation of larger amount of heat during hydration, which causes the undesirable increase of the temperature of the concrete $[18,19]$. Even that, with the presented problems, technical benefits with these systems in the cement matrix favor its use [13,15,20,21,22].

The agroindustrial ash affects the interfacial transition zone (ITZ) between aggregate and cement matrix by means of particle size distribution (decrease wall effect) and pozzolanic reactivity (increase quantity of calcium silicate hydrated). The ITZ is a usually region with a higher $\mathrm{W} / \mathrm{B}$ ratio, and thus a higher porosity, than the bulk paste. The cement and mineral addition particles in paste, which are suspended in the mix water, cannot pack together as efficiently when they are in the close vicinity of an aggregate particle. It is known to be the weakest region with deficit of cement particles in concrete [23]. For concrete to possess good mechanical performance, it is essential that the ITZ is designed to be as dense as possible, resulting in a good bond between the aggregate and the matrix [24]. Several researches present results demonstrating that the mineral additions can produce a significant reduction in the thickness of the matrix-aggregate interfacial transition zone (ITZ), i.e. higher densification of such region, contributing to an improvement of the properties related to mechanical strength and concrete durability [25-27]. However, the influence of sugarcane (bagasse and straw) industrial ashes (SCIA) on the ITZ of concrete has been rarely reported, which constitutes an important line of research for the scientific community. The SCIA can decrease porosity in the ITZ because it has particles size distribution from nanometers to millimeters that filling voids among coarse particles mainly in the aggregate and matrix interface. Moreover, during hydration process the SCIA can mitigate voids by means of pozzolanic reaction that consequently can fill the voids with calcium silicate hydrated (C-S-H) phase. Therefore, the aim of this study was

Table 1

Mix design of the cementitious matrix of the concretes.

\begin{tabular}{lllll}
\hline Series & W/B & $\begin{array}{l}\text { SF/C }(\%) \\
\text { (by mass) }\end{array}$ & $\begin{array}{l}\text { SCIA/C }(\%) \\
\text { (by mass) }\end{array}$ & $\begin{array}{l}\text { SPA/B (\%) } \\
\text { (by mass) }\end{array}$ \\
\hline 1 & 0.35 & - & - & 0.1 \\
2 & & 20 & - & 0.2 \\
3 & & - & 20 & 0.2 \\
4 & 0.55 & - & - & - \\
5 & & 20 & - & 0.1 \\
6 & & - & 20 & 0.1 \\
\hline
\end{tabular}

to evaluate the influence of the mix of cogeneration ashes from bagasse and straw sugarcane on mechanical properties of ITZ in concretes by nanoindentation technical analysis. Nanoindentation measures are being used as a good tool to evaluate properties micro and nanometer scale, such as hardness and indentation modulus in cement based materials [28-33].

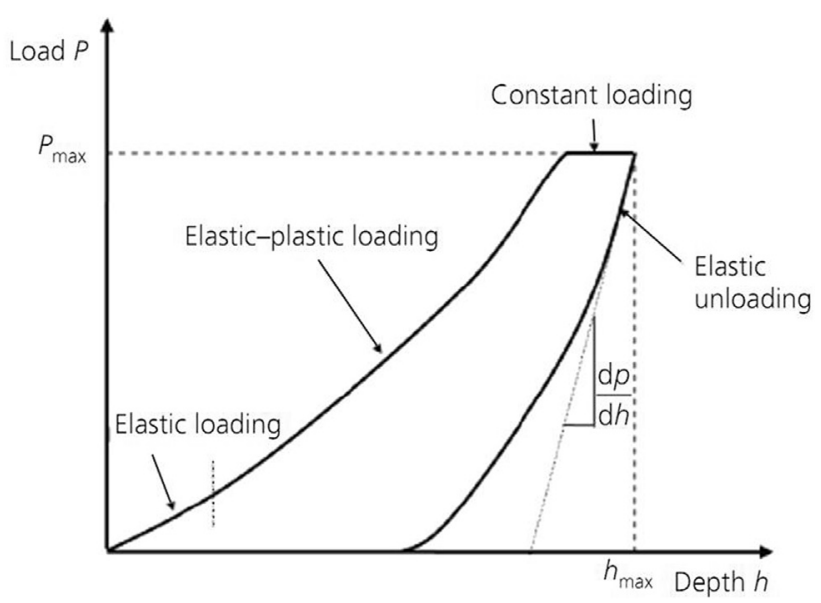

Fig. 1. A typical load-depth curve of the nanoindentation tests [42].

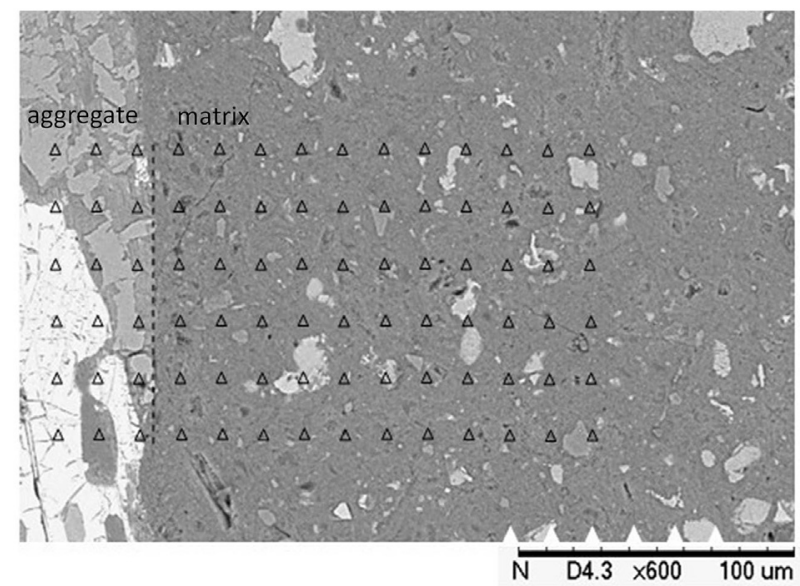

Fig. 2. Schematic diagram of indentation area of aggregate-matrix interfacial transition zone.

Table 2

Chemical composition by XRF of cement, SCIA and SF.

\begin{tabular}{llll}
\hline Element & Cement & SCIA & SF \\
\hline $\mathrm{SiO}_{2}$ & 19.1 & 60.14 & 84.50 \\
$\mathrm{Al}_{2} \mathrm{O}_{3}$ & 4.44 & 12.53 & 0.97 \\
$\mathrm{Fe}_{2} \mathrm{O}_{3}$ & 2.68 & 10.35 & 2.62 \\
$\mathrm{MnO}$ & $<0.10$ & 0.20 & 0.27 \\
$\mathrm{MgO}$ & 2.32 & 2.10 & 0.60 \\
$\mathrm{CaO}$ & 63.5 & 3.11 & 2.93 \\
$\mathrm{Na}_{2} \mathrm{O}$ & 0.36 & 0.16 & 0.15 \\
$\mathrm{SO}_{3}$ & 2.63 & 0.11 & - \\
$\mathrm{K}_{2} \mathrm{O}$ & 6.06 & 1.04 \\
$\mathrm{TiO}_{2}$ & 1.10 & 2.73 & 0.10 \\
$\mathrm{P}_{2} \mathrm{O}_{5}$ & 0.24 & 1.47 & 0.14 \\
$\mathrm{SrO}^{\mathrm{LOI}}$ & 0.21 & - & - \\
& 0.14 & 1.03 & 7.53 \\
\hline
\end{tabular}



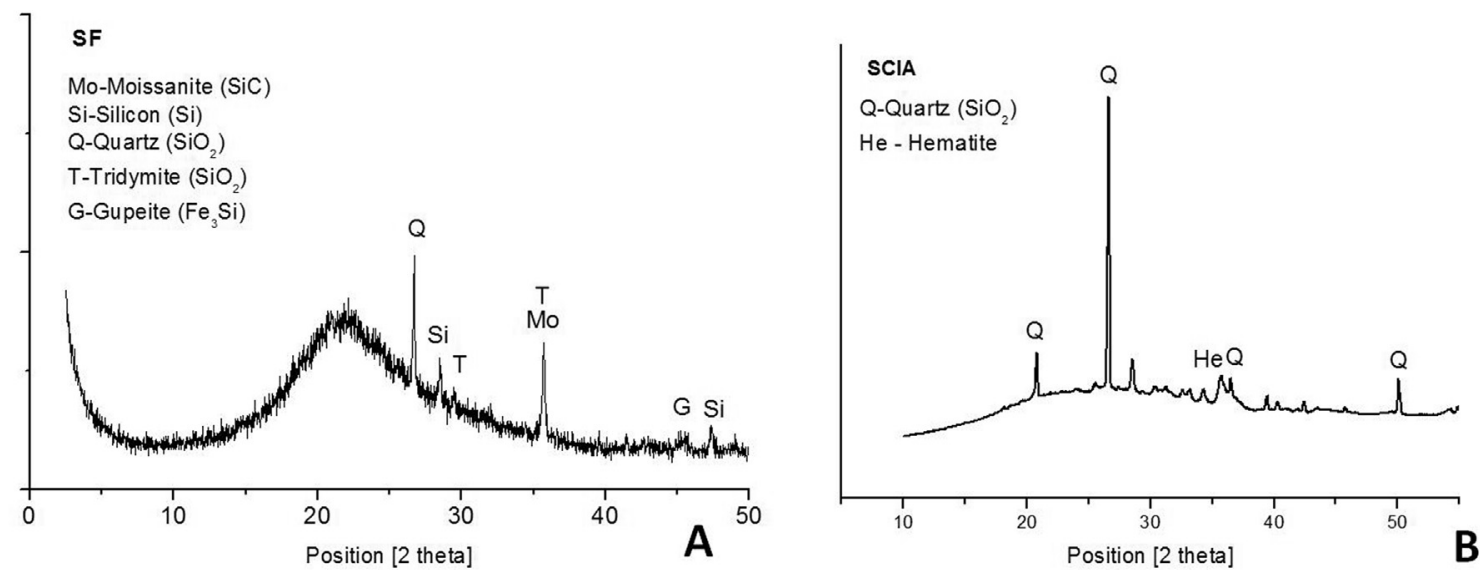

Fig. 3. $\mathrm{X}$ ray diffraction patterns: (A) SF and (B) SCIA.

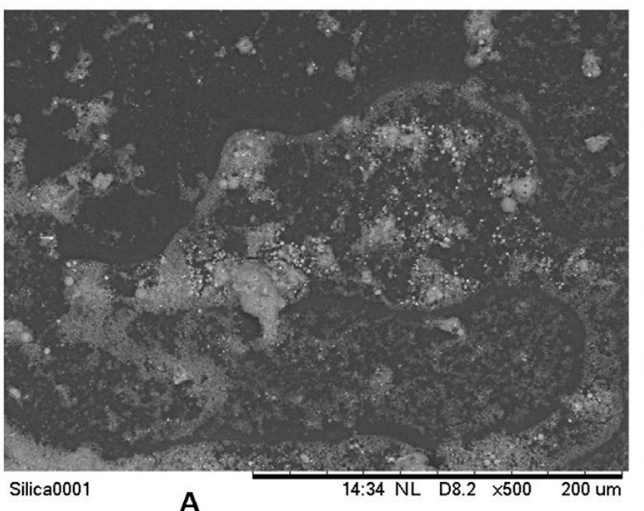

A

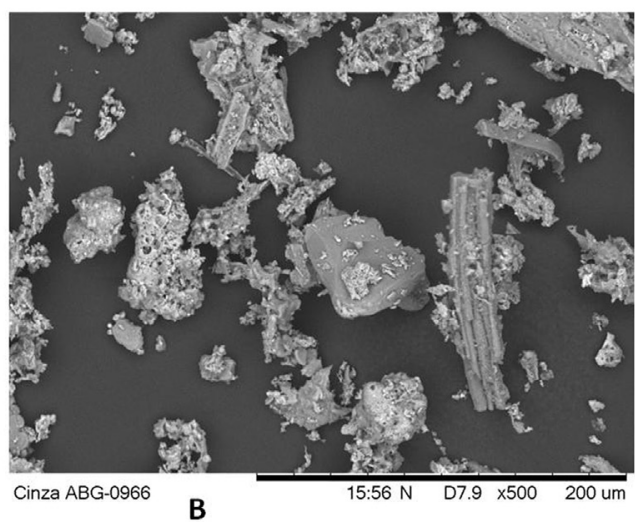

Fig. 4. SEM-ES micrographs showed morphology and size of the particles: (A) SF and (B) SCIA (silica skeleton and quartz contamination).

\section{Materials and methods}

\subsection{Materials}

It was used an ordinary Portland cement type V (OPC), with high initial strength, according to Brazilian standard ABNT NBR 5733 (chemical composition similar to ordinary Portland cement -

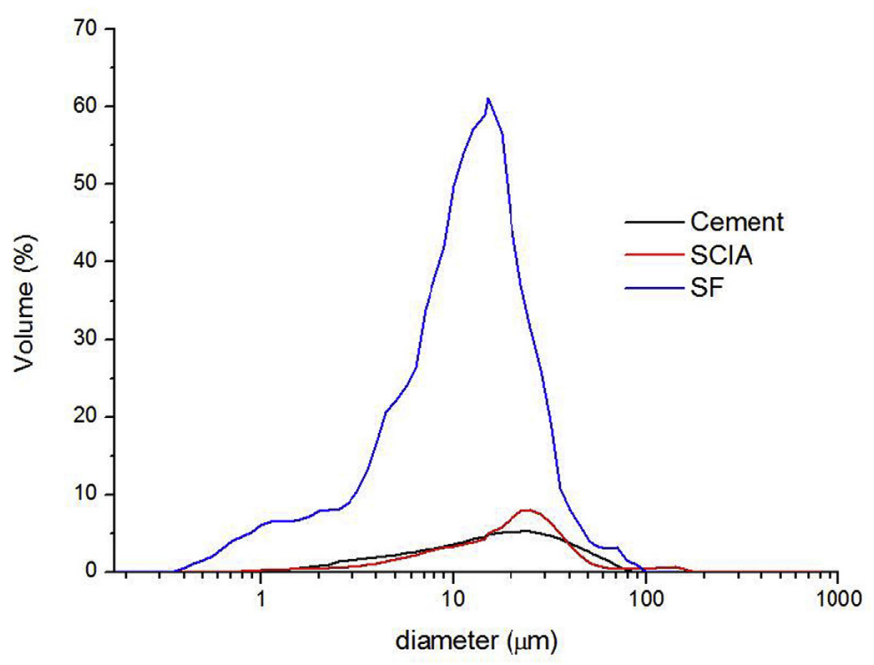

Fig. 5. Particle size distribution analysis of the raw materials.
Table 3

Equivalent diameter finer than a cumulative percent and specific surface area of the materials.

\begin{tabular}{|c|c|c|c|c|}
\hline \multirow[t]{2}{*}{ Raw materials } & $\mathrm{D}_{10}$ & $\mathrm{D}_{50}$ & $\mathrm{D}_{90}$ & \multirow{2}{*}{$\frac{\text { Specific surface area }}{\left(\mathrm{m}^{2} / \mathrm{g}\right)}$} \\
\hline & \multicolumn{3}{|c|}{$(\mathrm{mm})$} & \\
\hline Cement & 2.72 & 12.09 & 31.80 & 1.38 \\
\hline SCIA & 8.16 & 36.24 & 82.15 & 6.10 \\
\hline $\mathrm{SF}$ & 2.46 & 10.95 & 23.91 & 16.10 \\
\hline
\end{tabular}

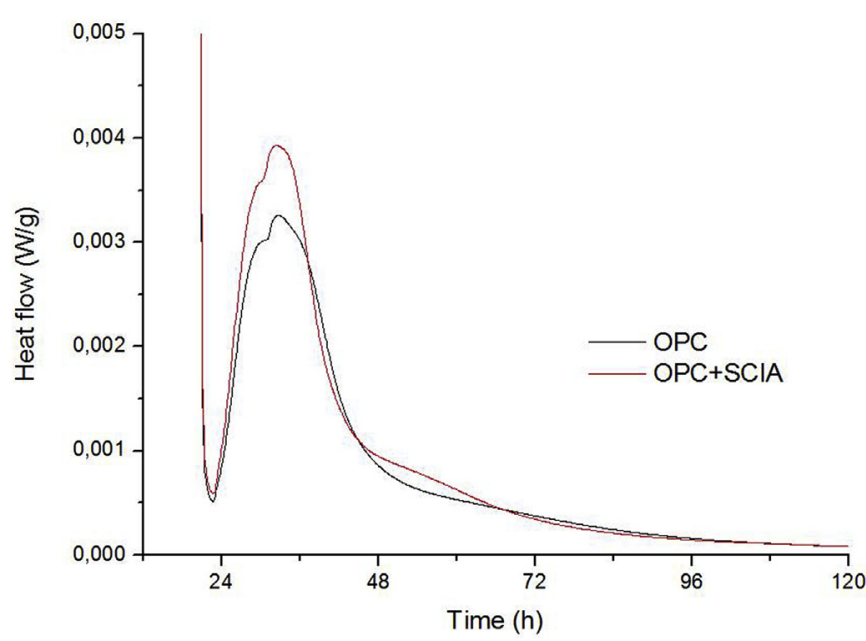

Fig. 6. Isothermal calorimetry analysis of pastes. 
ASTM C150) [34]. The sugarcane industrial ashes (SCIA) used in the present study came from the burning of bagasse and straw of sugarcane ( $50 \%$ by mass for each of them). The ashes were subjected to a second burning in laboratory controlled conditions in order to reduce as much as possible the presence of unburned organic matter. The ashes were air dried and subsequently calcined in a muffle furnace at $700{ }^{\circ} \mathrm{C}$ for $60 \mathrm{~min}$. The heating rate was $10^{\circ} \mathrm{C} /$ min, the cooling was slow. In sieving analysis was performed to assess the particle size distribution of the SCIA was below $45 \mu \mathrm{m}$ (325 mesh).

The silica fume (SF), M920D, Elkem, was used as a commercial

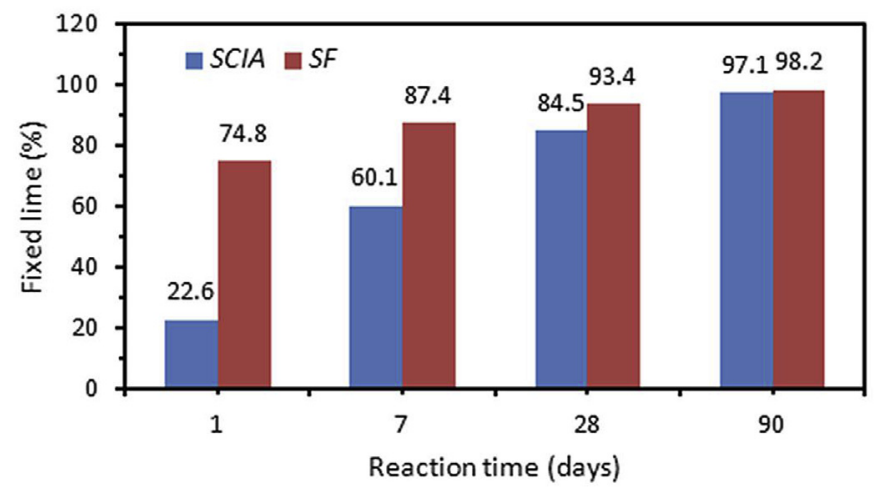

Fig. 7. Percentage of consumed fixed lime up to 90 days of pozzolanic reaction. pozzolan, besides that, a superplasticizer Melflux 2651 F 99(powder) was applied to improve the rheology of the cementitious matrix. The coarse aggregate chosen was basalt with diameter around $6.3-9.5 \mathrm{~mm}$. Fine aggregate was not used to prevent interference in the analysis of ITZ.

\subsection{Methods and instrumental techniques}

\subsubsection{Materials characterization}

The chemical characterization of the biomass ash was carried out by X-ray fluorescence (XRF), using a Philips PW-1404 and a ScMo X-ray tube. Fineness was analyzed by laser diffraction particle size analyzer (LRD), using a Sympatec Helos 12 KA spectrometer and isopropyl alcohol as non-reactive liquid. The mineralogical composition of the raw materials was determined by random powder X-ray diffraction technique (XRD) using a Bruker D8 Advanced, operating at a wavelength of 1.54 ( $\mathrm{CuK} \alpha$ radiation), $40 \mathrm{kV}$ and $50 \mathrm{~mA}$. The data were collected from $5^{\circ}$ to $60^{\circ}(2 \theta)$, with step of $0.02^{\circ}$, for $2 \mathrm{~h}$, rotating the samples at $15 \mathrm{rpm}$. Morphological characterization was carried out using a Zeiss AXIO Imager A2m SEM-SE.

Nitrogen adsorption-desorption isotherms were measured with a Micromeritics ASAP 2010 analyzer. A sample degassing at $50{ }^{\circ} \mathrm{C}$ for $24 \mathrm{~h}$ was performed previous to every measurement. Specific surface area values were calculated from the isotherm data using the Brunauer-Emmett-Teller (BET) method in a relative pressure range of $0.003-0.3$.

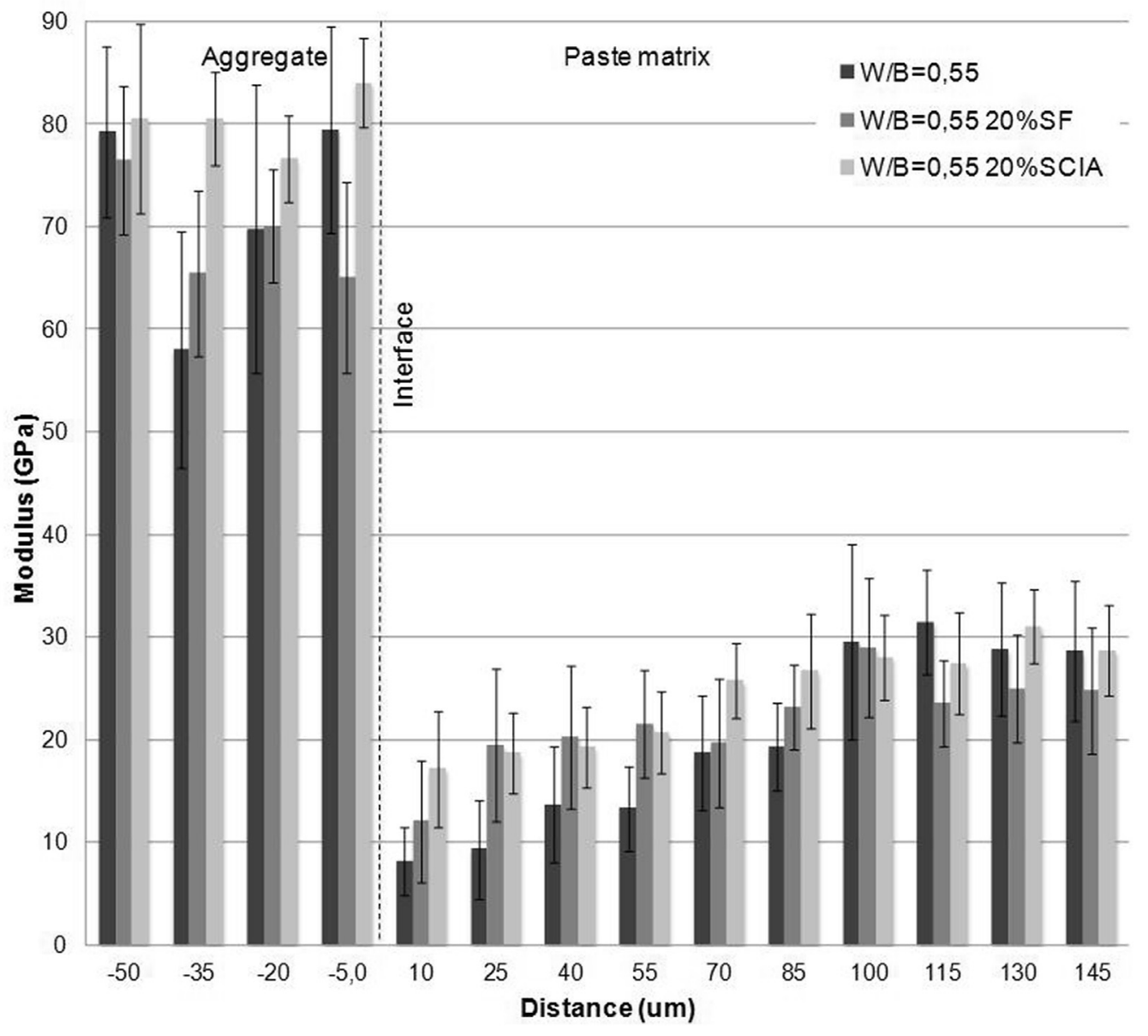

Fig. 8. Grid indentation modulus on ITZ in concrete with $\mathrm{W} / \mathrm{B}=0.55$. 


\subsubsection{Isothermal calorimetry and pozzolanic evaluation}

Calorimetry analysis was done, using a thermometric equipment TAM AIR, with the purpose to evaluate if the ash has an influence on Portland cement hydration process at $23{ }^{\circ} \mathrm{C}$ for $120 \mathrm{~h}$. Cementitious paste with and without the SCIA addition were produced. Cement pastes were produced with Portland cement (100\%) using the ratio $\mathrm{W} / \mathrm{B}=0.4$ and Portland cement pastes $(80 \%)$ and SCIA (20\%) using the same $\mathrm{w} / \mathrm{c}$ ratio.

A non-standard accelerated chemical method was used to study the pozzolanic activity of these materials [35]. This method consists in putting the pozzolan $(1 \mathrm{~g})$ in contact with the lime-saturated solution $(75 \mathrm{~mL})$ at $40{ }^{\circ} \mathrm{C}$ for $1,7,28$ and 90days. After each period of reaction, the content of fixed lime was quantified as the difference between the $\mathrm{CaO}$ concentration in the original solution $(17.68 \mathrm{mmol} / \mathrm{L})$ and the concentration in the test solution. Quantification was performed by titration of aqueous $\mathrm{Ca}^{2+}$ and $\mathrm{OH}^{-}$with ethylenediaminetetraacetic acid (EDTA) and diluted $\mathrm{HCl}$, respectively, according to the methodology specified in European standard 196-5 [36].

\subsubsection{Concrete preparation}

Six concrete mixes design with 1:0.5 ratio cement matrix to aggregate were prepared at a water/binder (W/B) ratio of 0.35 and 0.55 (Table 1). The content of the silica fume (SF) and sugarcane industrial ashes (SCIA) was $20 \%$ by mass of the Portland cement content. Superplasticizer (Melflux 2651 F 99) at a dosage around $0-0.2 \%$ per mass of binder (SPA/B) was added to the fresh concrete with the objective to improve the workability and to obtain a selfcompacting behavior. The materials were added in a planetary mixer and mixed for 3 min.

The PVC molds for casting cylinder specimens (25-diameter $\mathrm{x}$ $50 \mathrm{~mm}$ ) on a vibration table were used. After demolding at $24 \mathrm{~h}$, the specimens were immersed in water for 2 days and subsequent air curing at $23 \pm 2{ }^{\circ} \mathrm{C}$ and relative humidity (RH) of $60 \%$ until complete 90 days.

\subsubsection{Specimens preparation}

For nanoindentation test and scanning electron microscopy (SEM) analyses samples of $10 \times 10 \times 10 \mathrm{~mm}$ were cut with a precision cutter (Struers) to avoid microcracks from cylinders in such a way that the investigated surface was parallel to the top surface of the cylinders. The analyses were carried out the center of the each sample. Tests were performed in 90-day-old specimens. Hydration was interrupted by ethanol (immersed for $24 \mathrm{~h}$ ). The slices were then removed from the ethanol and were subjected to a heat treatment (drying) of $60{ }^{\circ} \mathrm{C}$ for $8 \mathrm{~h}$. The specimens were impregnated under vacuum with a low-viscosity epoxy resin in a $25.4 \mathrm{~mm}$ diameter rubber mold. The vacuum to the chamber was then released, allowing atmospheric pressure to facilitate impregnation. The rubber mold with the specimen was then removed from the vacuum chamber and cured for $24 \mathrm{~h}$ in ambient temperature.

Special attention was given the quality of the polished sample surface so that the indentation modulus and the hardness can be measured with nanoindentation technique $[30,37,38]$. In this study,

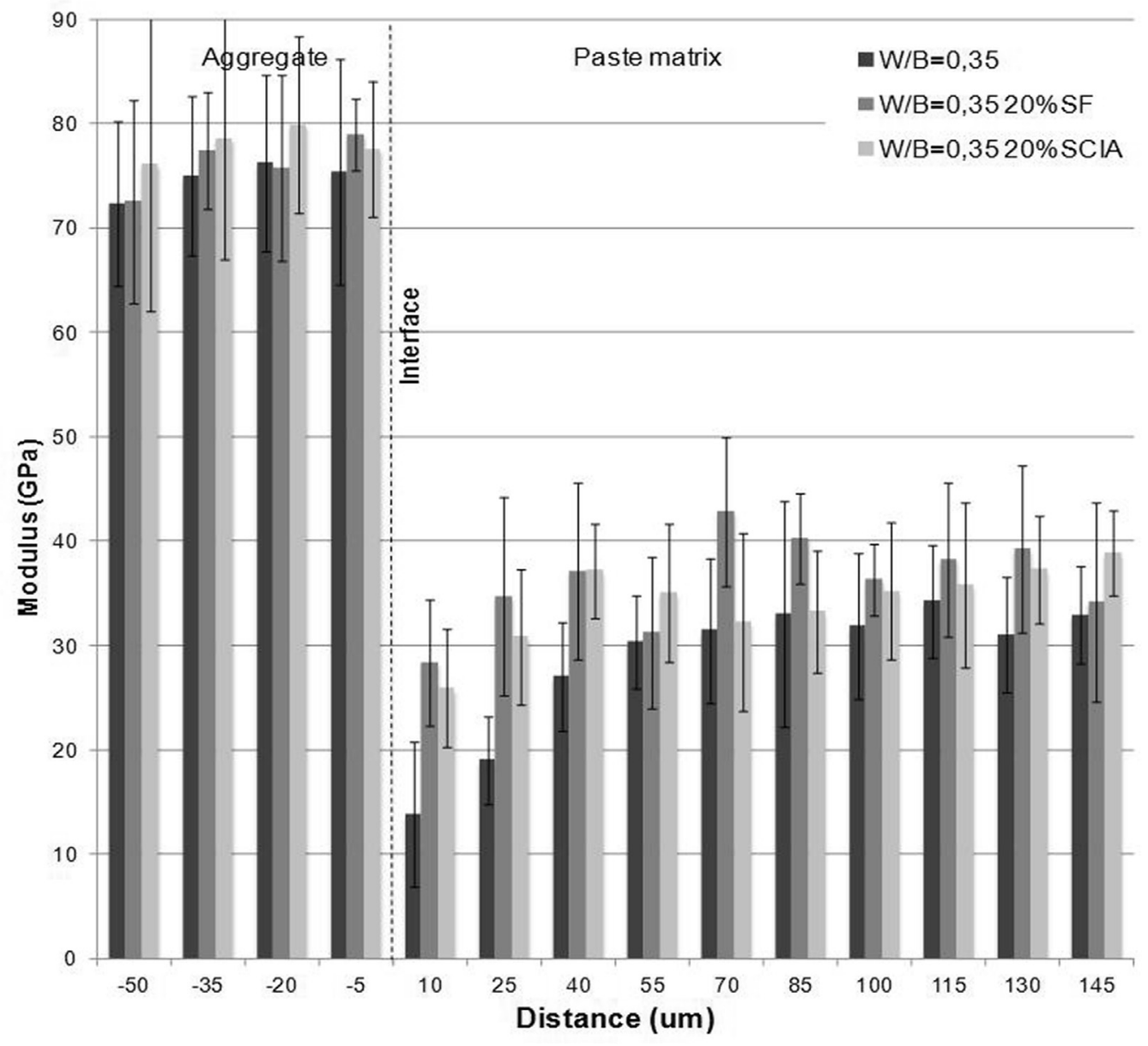

Fig. 9. Grid indentation modulus on ITZ in concrete with $\mathrm{W} / \mathrm{B}=0.35$. 
the samples were initially polished on SiC abrasive paper disks with gradation P1000 $(18.3 \mu \mathrm{m})$ for approximate $10 \mathrm{~min}$ using a semiautomatic polishing equipment of the Struers, model Tegra-Force. Ethanol was used as the cooling medium and lubricant. The sample was then cleaned in ethanol in an ultrasonic cleaner before polishing. After a variety of polishing compounds and polishing mats, one combination can provide a repeated success by lengthy polishing (100 rpm) under light load (10 N) [38]. Therefore, the final polishing was carried out using diamond polishing compound. It was used the same semi-automatic-polisher and diamond suspensions in ethanol solution with narrow micrometer-sized particles of $6 \mu \mathrm{m}, 3 \mu \mathrm{m}$ and $1 \mu \mathrm{m}$. The relatively slow polishing speed was applied to mitigate damage and allowed a fine finishing on the sample surface. Each step spent approximately $10 \mathrm{~min}$. An ultrasonic bath cleaning in ethanol was performed for 10 min to remove all dust and diamond particles after each step of polishing. After polishing, the surface quality was confirmed using an Zeiss optical microscope and then the sample was stored in a small air-tight container.

\subsubsection{Nanoindentation testing}

It was used the nanoindenter NANOVAE indenter configured with a Berkovich tip (radius of $0.6 \mu \mathrm{m}$, angle of $142.3^{\circ}$ ). The nanoindenter system was calibrated by indenting a silica sample. The test locations were guided by means of an incorporated optical microscope. The head repositioning was carried out before each indentation.
All tests were programmed in a single cycle loading way that the indenter came into contact with the sample surface with the load increased at a constant rate of $166.7 \mu \mathrm{N} / \mathrm{s}$ and the maximum load was $5000 \mu \mathrm{N}$. The maximum load was applied for $10 \mathrm{~s}$ and each time of loading and unloading strength was $30 \mathrm{~s}$.

The nanoindentation test was performed to depth around 250-600 nm. According to some researches [32,39,40], these depth values are adequate to the analysis of the hydrated cement products. Each load/displacement diagram was plotted and inspected to evaluate some problems, such as abnormal or discontinuous shapes $[29,38,39,41,42]$.

Fig. 1 shows a typical load-depth curve which was generated from the loading with an initial increasing loading, followed by holding and then decreasing loading.

The indentation modulus $(\mathrm{M})$ and the hardness $(\mathrm{H})$ can be obtained from the initial slope of the elastic unloading stage in the load-depth curve, as defined in Equations (1) and (2) [42]:

$\boldsymbol{M}=\frac{1}{2}\left(\frac{\boldsymbol{d p}}{\boldsymbol{d h}} \frac{\sqrt{\pi}}{A}\right)_{(h=h \max )}$

$\boldsymbol{H}=\left(\frac{\boldsymbol{p}}{\boldsymbol{A}}\right)_{(h=h \max )}$

where $p$ is the indentation load, $h$ is the indentation depth, $h_{\max }$ is the maximum indentation load and $A$ is the projected contact area, which can be extrapolated from the indentation depth $\mathrm{h}$ using the

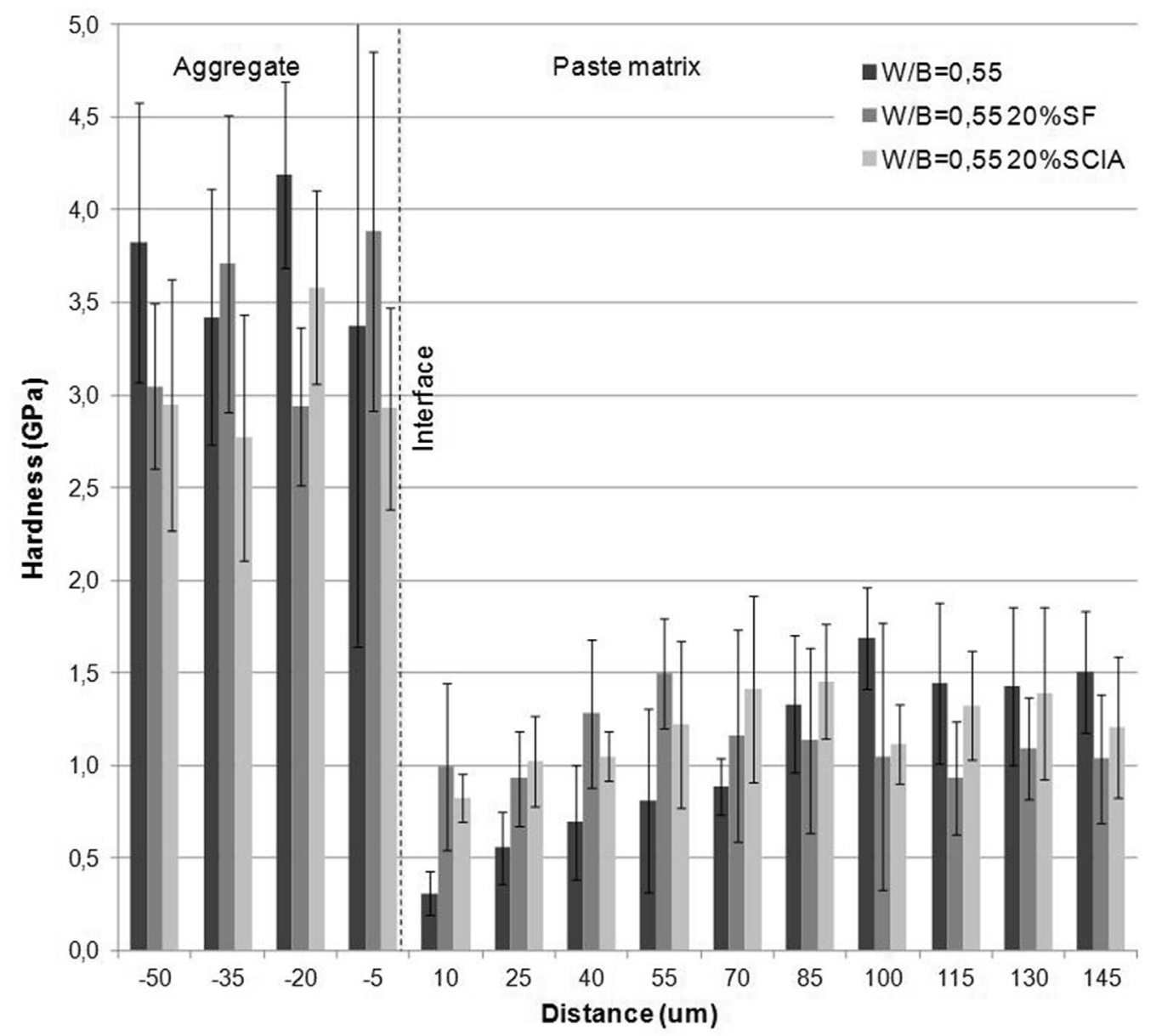

Fig. 10. Grid indentation hardness on ITZ in concrete with $W / B=0.55$. 
method of Oliver and Pharr (1992) [43].

The spacing between indents was $15 \mu \mathrm{m}$ (horizontal) and $20 \mu \mathrm{m}$ (vertical). The indent areas had the dimensions of $195 \times 100 \mu \mathrm{m}$ (Fig. 2) and 84 indents were made in an array in each studied area.

The thickness of ITZ was defined as the distance between the aggregate-matrix interface where the values of the nanomechanical properties (indentation modulus and hardness) are instable i. e. where there is a great variation in the values. In the extremity of the ITZ (in the aggregate or cement matrix bulk), for example, the hardness values are more stable. For this reason, it is difficult to define exactly the thickness of ITZ.

\section{Results and discussion}

\subsection{Characterization of raw materials}

The chemical composition of raw materials by XRF is shown in Table 2. The chemical composition requirement for a pozzolan is to present a minimum content of $50 \%$ by mass for the sum of the reactive oxides $\left(\mathrm{SiO}_{2}+\mathrm{Al}_{2} \mathrm{O}_{3}+\mathrm{Fe}_{2} \mathrm{O}_{3}\right)$, according to the ASTM C-618 [44]. The sum of the reactive oxides for the SCIA was of $83.02 \%$, value closer to that of SF (88.09\%). The reactive silica content in SCIA was $49.52 \%$ of total, percentage higher than that required in European standard of minimum of $25 \%$ for pozzolan (siliceous fly ash, natural and calcined ones) [45]. Loss of ignition (LOI) of SCIA was approximately 7 times lower in comparison to SF. This characteristic has a positive effect on the rheological properties of the blended cements (water demand and setting times).
Fig. 3 shows the XRD patterns of the pozzolans (SF and SCIA), showed the mineralogical composition by presence of amorphous and crystalline phases. In the XRD pattern of the SCIA were identified mainly crystalline phases, such as quartz (main peaks at 26.65-2 $\theta$ and 20.89-2 $\theta$ ) and hematite (35.72-2 $\theta$ ). In the XRD pattern of the SF were identified amorphous phase and some crystalline phases, such as quartz $(26.82-2 \theta)$, moissanite (35.76-

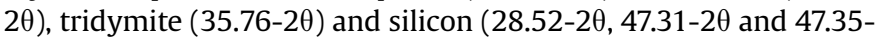
$2 \theta$ ). The halo in the XRD pattern of the SF characterizes the amorphicity of this material can be seen in Fig. 3A and in different proportion the amorphorcity was observed in the XRD pattern of the SCIA (Fig. 3B). Part of the crystalline phases identified in the SCIA was due to the presence of sand contamination harvested with sugarcane bagasse waste used as biomass.

It is well known that the morphology of pozzolans depends directly on the nature of the biomass, industrial process and burning temperature. A morphological study of the starting pozzolans carried out by SEM is illustrated in Fig. 4, showing different morphology and size of the particles. SCIA has particles with irregular geometry and more porosity than that shown by SF, mainly due to its silica skeleton formed after burning. Besides, SCIA contents some quantity of quartz contamination. This observation stated the fineness was observed by particle size analysis and BET technique [46].

Fig. 5 shows the size particle distributions of the materials by laser diffraction particle size analyzer. It was determined that $10 \%$, $50 \%$ and $90 \%$ of the particles are smaller than a specific equivalent diameter value of the samples as presented in Table 3. It is observed

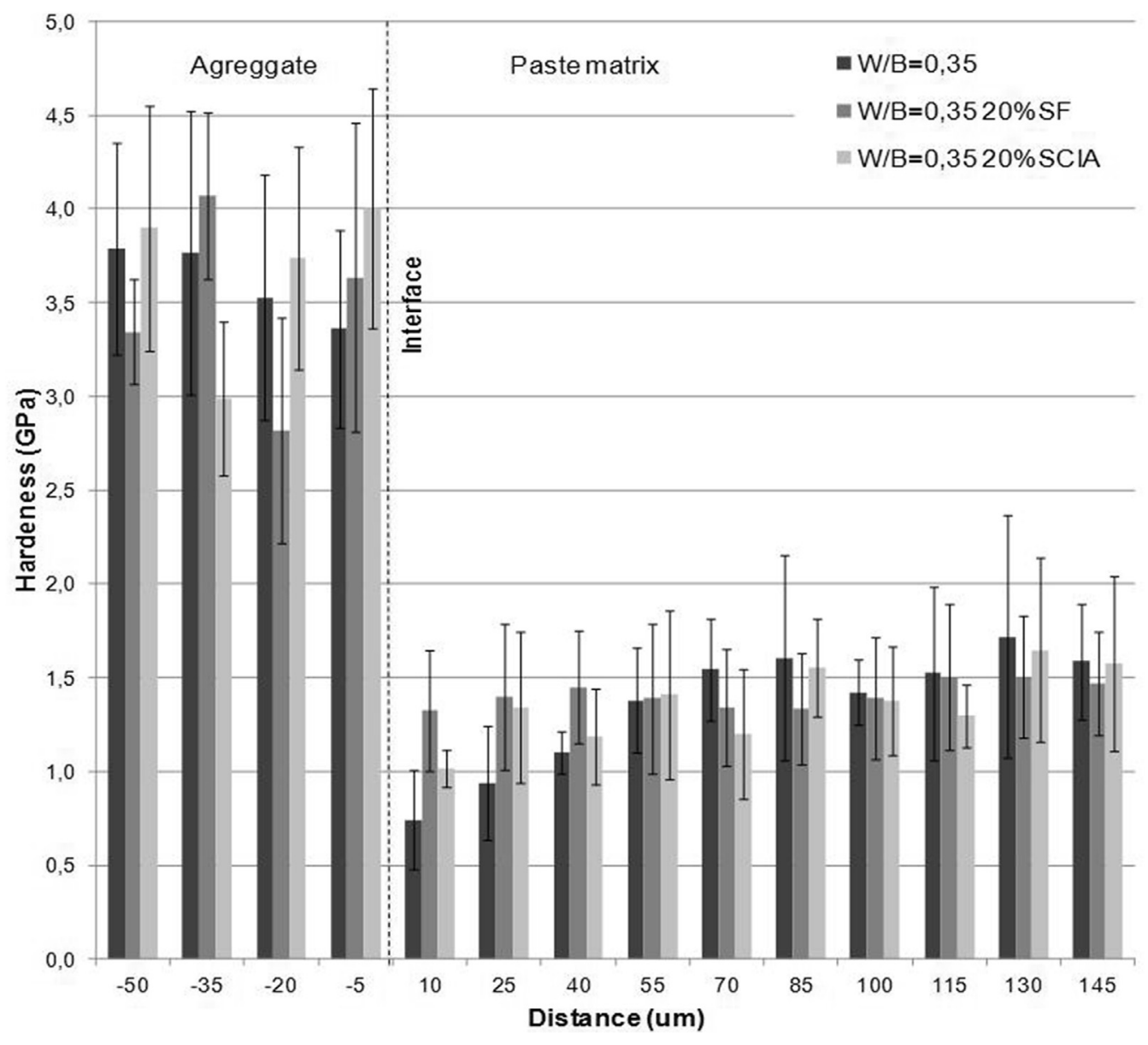

Fig. 11. Grid indentation hardness on ITZ in concrete with $W / B=0.35$. 
that the Portland cement and SCIA curves are overlap, which shows that may occurs a packaging effect in the samples; $90 \%$ of the ashes are above $82 \mu \mathrm{m}$. The specific surface area analysis present in Table 3, shows that specify surface area of the SCIA is greater than cement, which was already expected, because it is more porous, attribute to the vegetable structure. The surface area of SF is the largest among them, since it is the sample with greater fineness. SEM are presented in Fig. $4 \mathrm{~A}$ and $\mathrm{B}$, it is possible to see that SF is thinner and is presented in the spheroidal shape, while the SCIA has a very different structure with grains in different formats.

\subsection{Physical and chemical behavior of the blended pastes}

Fig. 6 shows the isothermal calorimetry curve of cement paste and SCIA/cement paste. It is noted that the inclusion of ash in fresh paste do not causes the delays setting time of the ordinary Portland cement. Furthermore, the generated heat flux of the paste with ash increased. According to Frias et al. (2007) [47] mineral additions with high pozzolanic activity in cement pastes increase

A
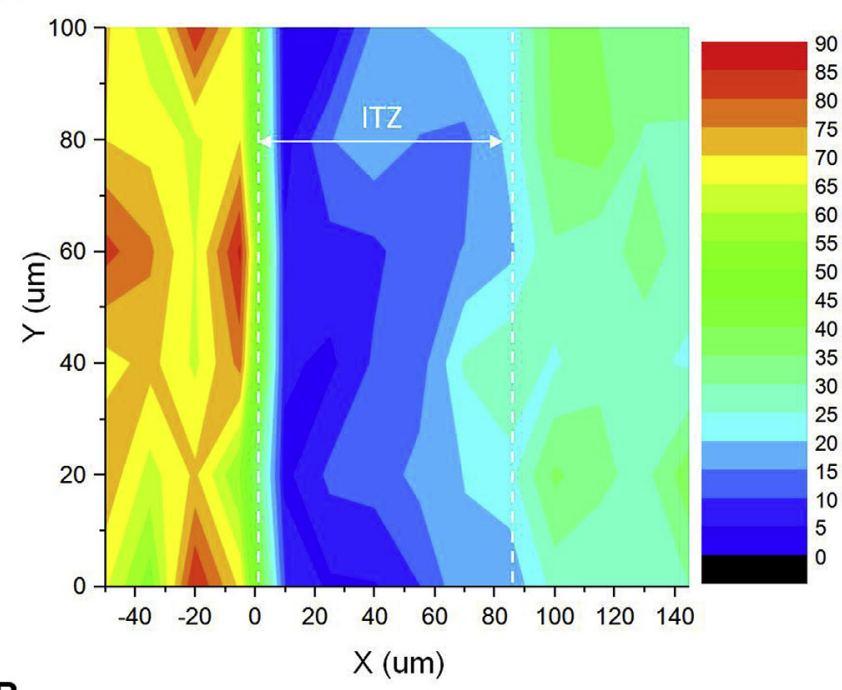

B

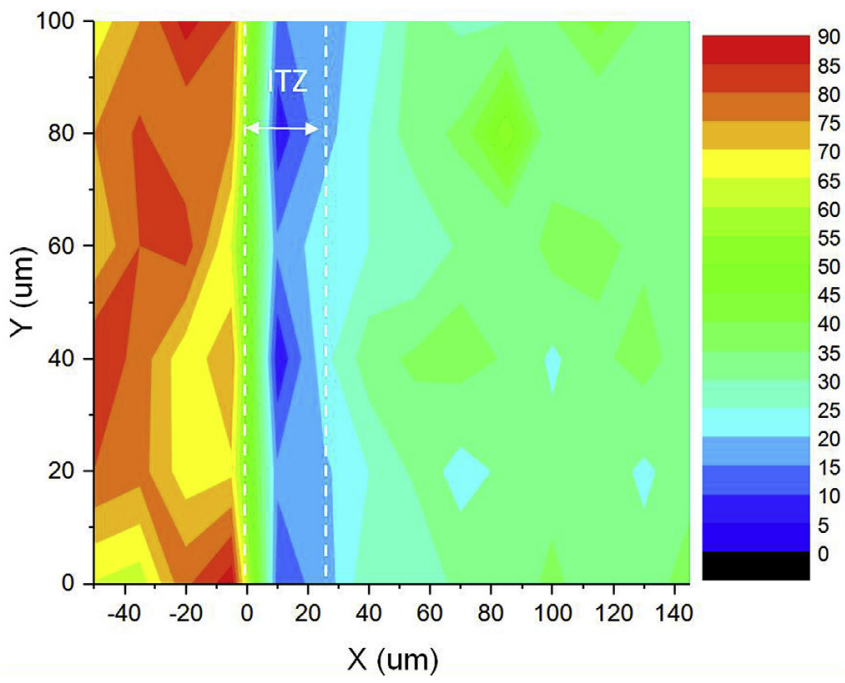

Fig. 12. Contour map of indentation modulus in reference concrete (GPa); (A) W/ $\mathrm{B}=0.55$; (B) $\mathrm{W} / \mathrm{B}=0.35$. temperature, in the curing process in early age, due to the combined effect of the exothermic reactions of the hydration and pozzolanic processes.

The results obtained of the consumed fixed lime with hydration reaction time for two pozzolans (SF and SCIA) are shown in Fig. 7. The pozzolan SF showed a higher pozzolanic activity than the SCIA up to 28 days, showing the maximum differences during the first $24 \mathrm{~h}$. At this age, the fixed lime for the SCIA and SF was 22.6 and $74.8 \%$ of available lime in dissolution, representing $69.8 \%$ less activity for SCIA ash.

However, this difference in values of fixed lime is progressively reduced with increasing hydration reaction time. At 90 days, the fixed lime values found in both cases were very similar. The different reaction rate between SF and SCIA was closely related to characteristics of theses pozzolans, such as quantitative of amorphous and crystalline phases and particle size distributions. The SF material is more amorphous and finesses than SCIA material, according to results indicated in Figs. 4 and 5, respectively. Despite these differences found with respect to the more reactive commercial silica fume, SCIA had high values of fixed lime from 7 days of reaction. This pozzolanic behavior was similar to other

A

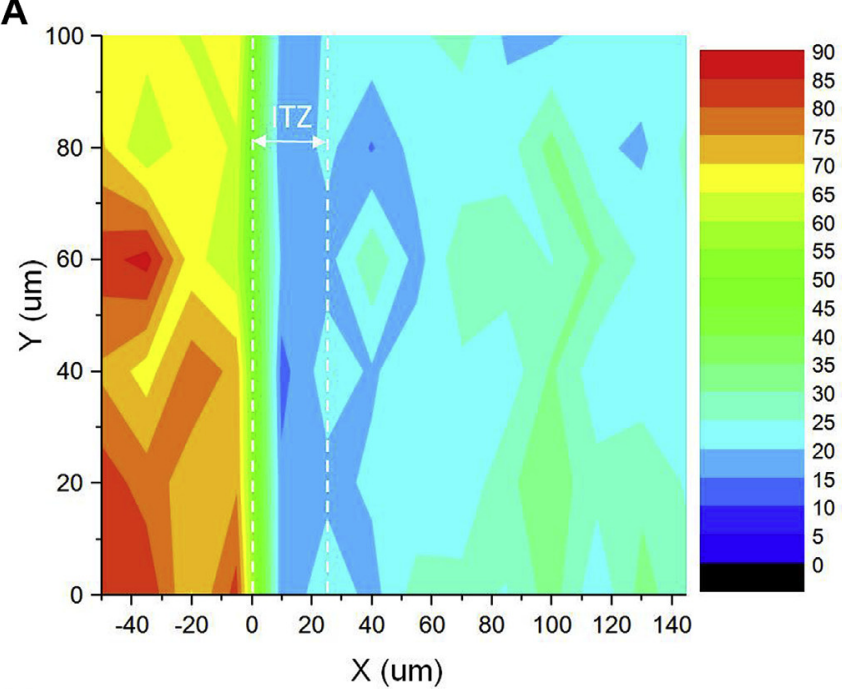

B

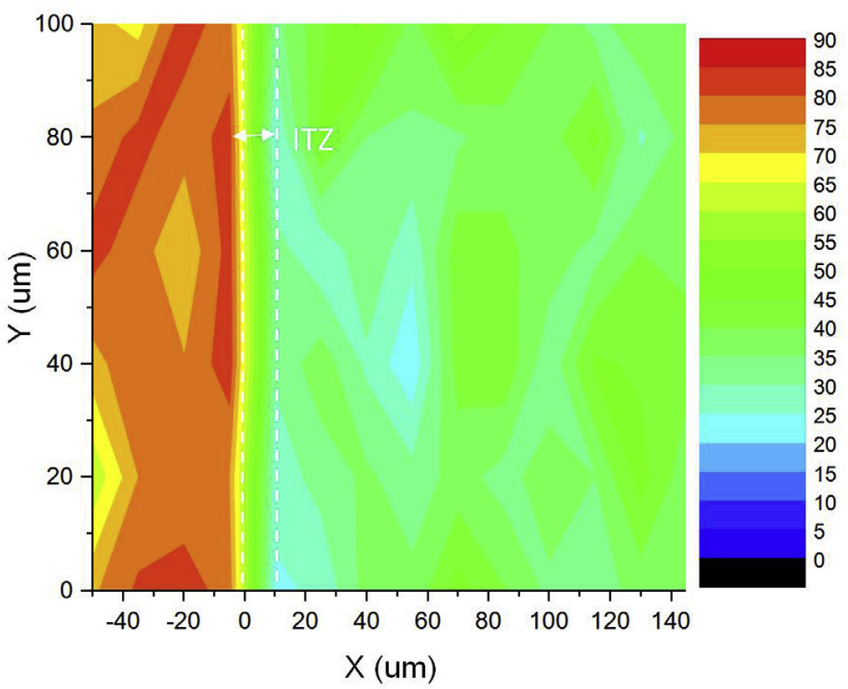

Fig. 13. Contour map of indentation modulus in concrete with $20 \%$ silica fume (GPa); (A) $\mathrm{W} / \mathrm{B}=0.55$; (B) $\mathrm{W} / \mathrm{B}=0.35$ 
agroindustrial ashes (originated from thermally activated elephant grass, e.g.) [48].

\subsection{Characterization of the ITZ}

Figs. 8-17 shows the distribution in the indentation modulus and hardness measured in the ITZ by means of the nanoindentation in studied concretes. In Figs. 8-11 the results were separated in three regions: aggregate, interface and paste matrix. It is found that behavior of indentation modulus distribution was close to that hardness across of ITZ. The ITZ thickness obtained of the reference concrete is approximately $25 \mu \mathrm{m}(\mathrm{W} / \mathrm{B}=0.35)$ and $85 \mu \mathrm{m}(\mathrm{W} /$ $\mathrm{B}=0.55$ ). These values are very close to the values obtained in some researches about concretes without mineral addition $[25,27,49]$.

The values of indentation modulus (8-18 GPa) and hardness (0.3-0.9 GPa) observed across the ITZ in reference concrete were corroborated with those reported in research papers $[30,39,40]$. According to Mondal (2008) [40] and $\mathrm{Hu}$ et al. (2014) [42], the average indentations moduli of the four main phases present in cement paste are approximately $10 \mathrm{GPa}$ for porous phase, $16 \mathrm{GPa}$ for

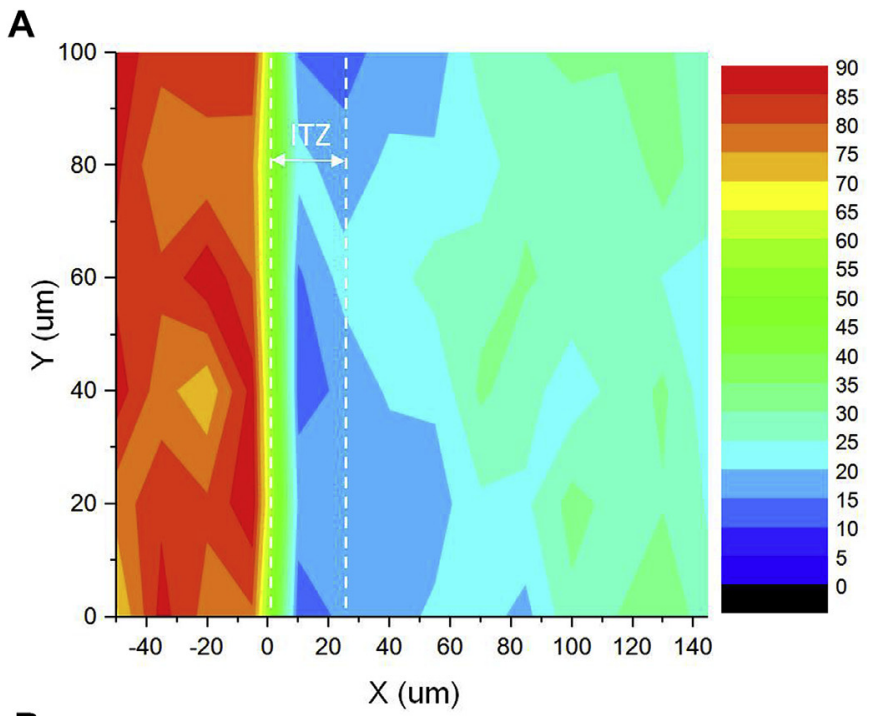

B

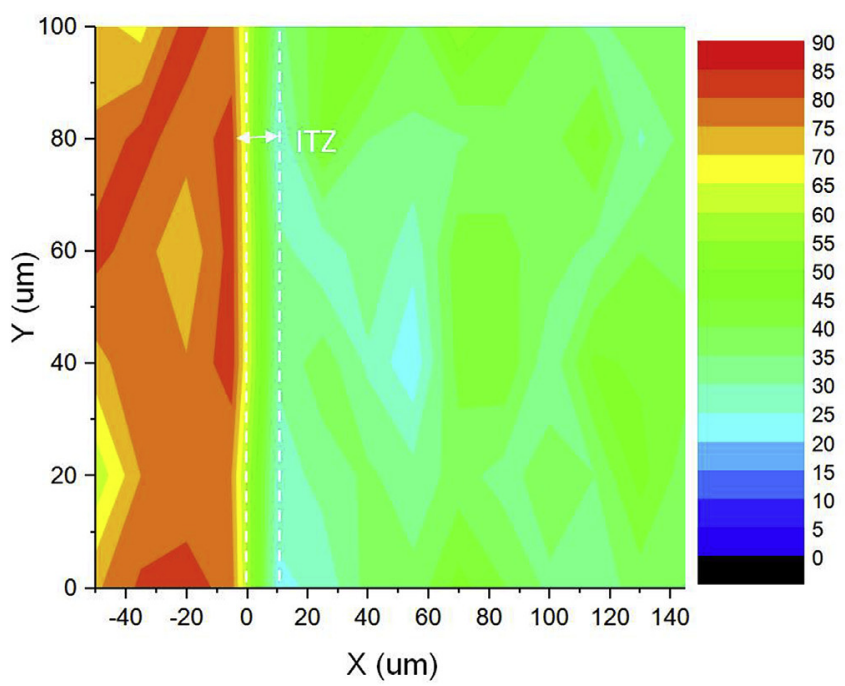

Fig. 14. Contour map of indentation modulus in concrete with $20 \%$ sugarcane industrial ashes $(\mathrm{GPa}) ;(\mathrm{A}) \mathrm{W} / \mathrm{B}=0.55 ;(\mathrm{B}) \mathrm{W} / \mathrm{B}=0.35$.
A

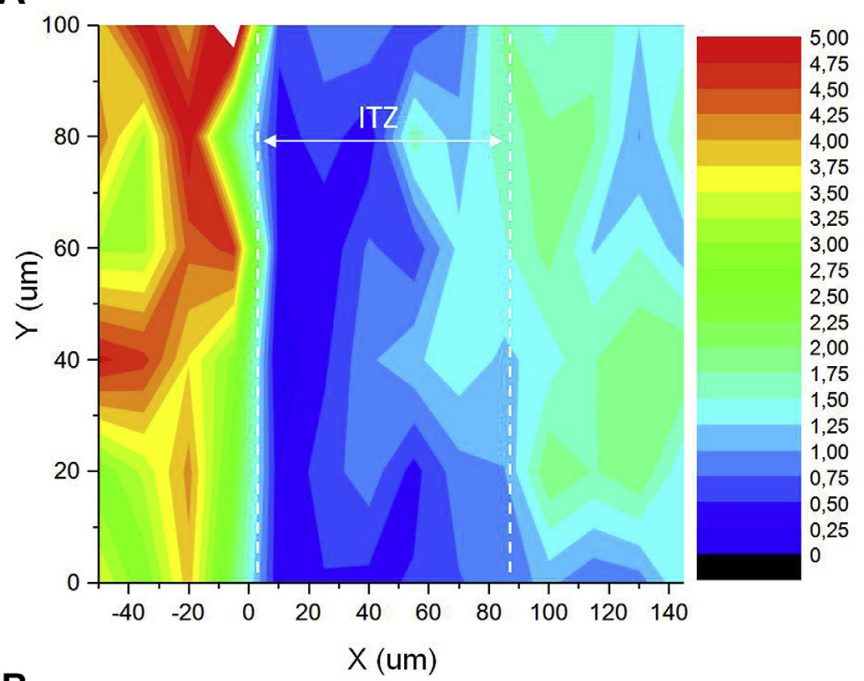

B

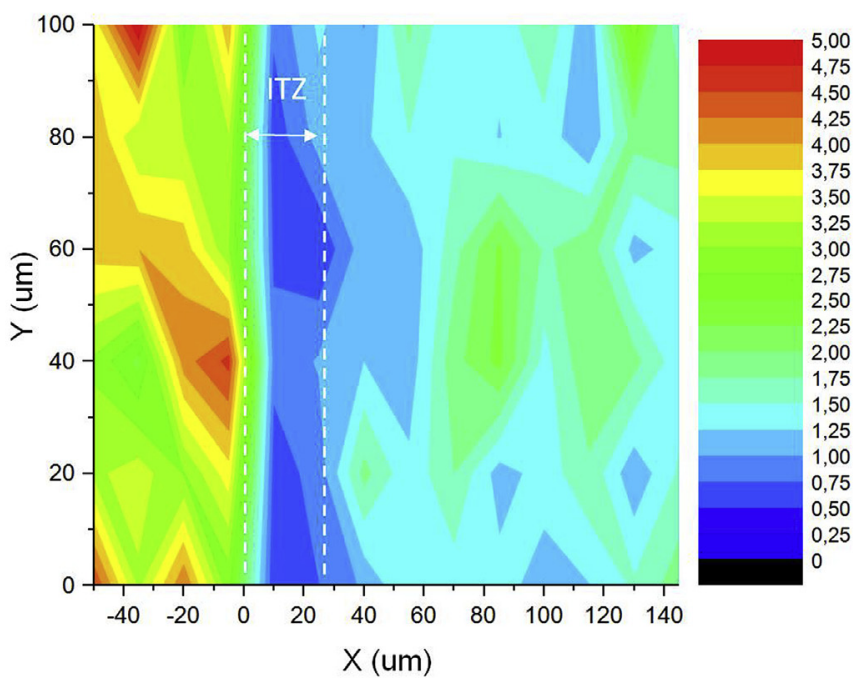

Fig. 15. Contour map of indentation hardness in reference concrete (GPa); (A) W/ $\mathrm{B}=0.55$; (B) $\mathrm{W} / \mathrm{B}=0.35$.

first type of C-S-H phase (low stiffness), 26 GPa for second type of C-S-H phase (high stiffness) and 35 GPa for calcium hydroxide.

The results demonstrated that the utilization of either silica fume or SCIA causes a similar and significant reduction in the matrix-aggregate ITZ thickness in comparison to the reference concrete, which can be observed in the elevation of the values of the indentation modulus and hardness in the region near to the aggregate (Figs. 9-11).

In the concrete with silica fume or SCIA, the values of the matrix-aggregate ITZ thickness were approximately $10 \mu \mathrm{m}(\mathrm{W} /$ $\mathrm{B}=0.35)$ and $25 \mu \mathrm{m}(\mathrm{W} / \mathrm{B}=0.55)$, which represents a reduction of approximately $70 \%$ of the thickness of ITZ compared to the reference concrete.

In the contour maps of indentation modulus and hardness of ITZ (Figs. 12-17) can be seen the difference between ITZ thickness in reference concrete and concrete with mineral additions (SF or SCIA). This fact can be observed by reducing in the low values of indentation modulus and hardness (blue coloration) in the region of ITZ and the increase in the high values of indentation modulus and hardness (yellow and green color) in the concretes with SF or SCIA. 
A

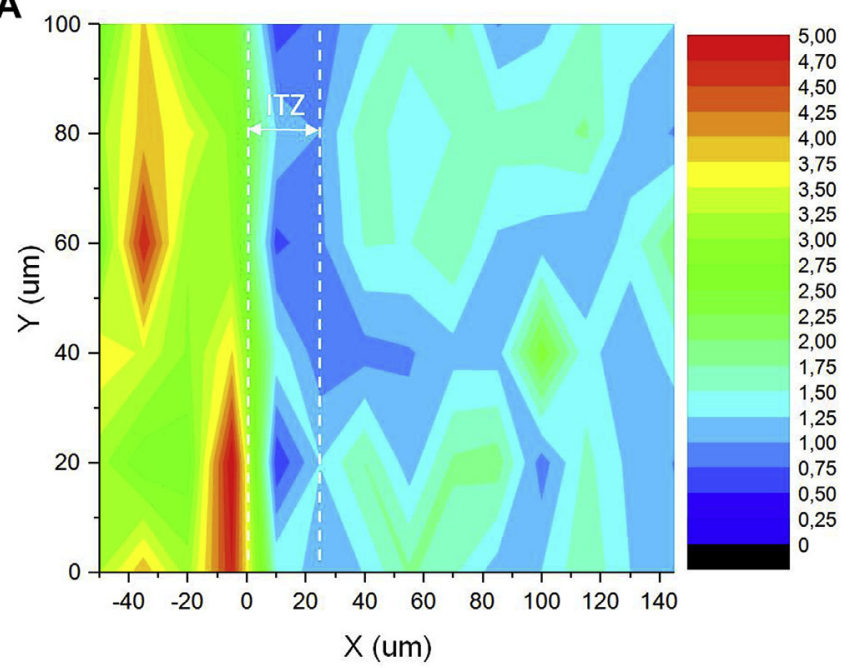

B
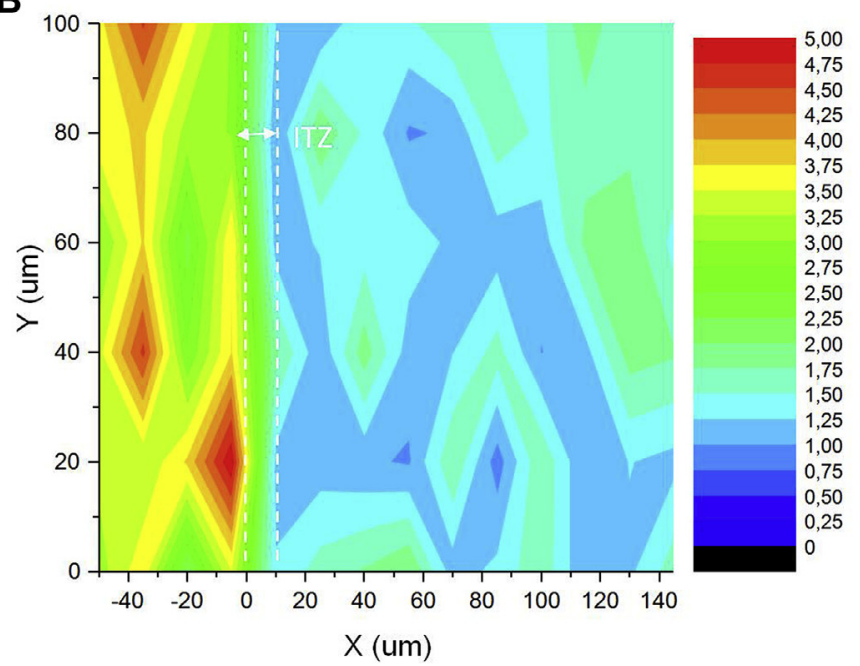

Fig. 16. Contour map of indentation hardness in concrete with $20 \%$ silica fume (GPa); (A) $\mathrm{W} / \mathrm{B}=0.55$; (B) $\mathrm{W} / \mathrm{B}=0.35$.

The thickness reduction in the ITZ with the utilization of silica fume or SCIA can be explained by the following points: less permeability of the fresh concrete, causing less water accumulation in the aggregate surface (wall effect); the occurrence of several crystallization nuclei, which contributes to the formation of smaller calcium hydroxide crystals with a higher crystallization tendency in random orientations; and the progressive densification of the hydration products by means of pozzolanic reaction [10,25,27,47].

According to the results, the SCIA has a similar behavior to the silica fume to the reduction capacity of ITZ thickness. This good behavior of industrial ash (SCIA) would be in agreement with the similarity of fixed lime results obtained at 90 days of reaction (Fig. 7), in which the fixed lime in both cases were between 97 and $98 \%$ of available lime.

\section{Conclusions}

Under the conditions and scopes of this experimental study the conclusion can be drawn in the following:

- Chemical analysis of the industrial ash (SCIA) obtained when a mix of sugarcane bagasse and straw waste are used as biomass
A

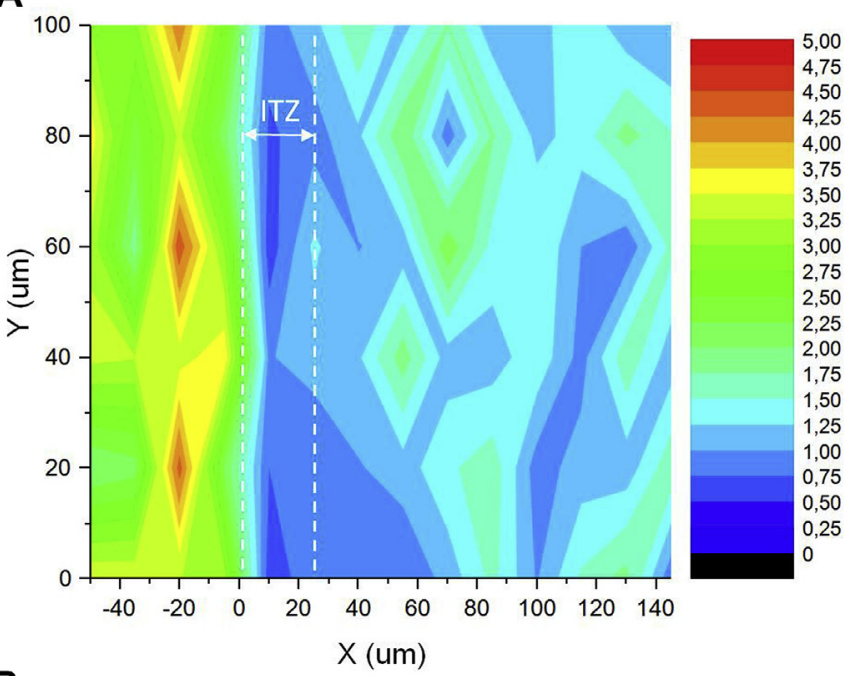

B

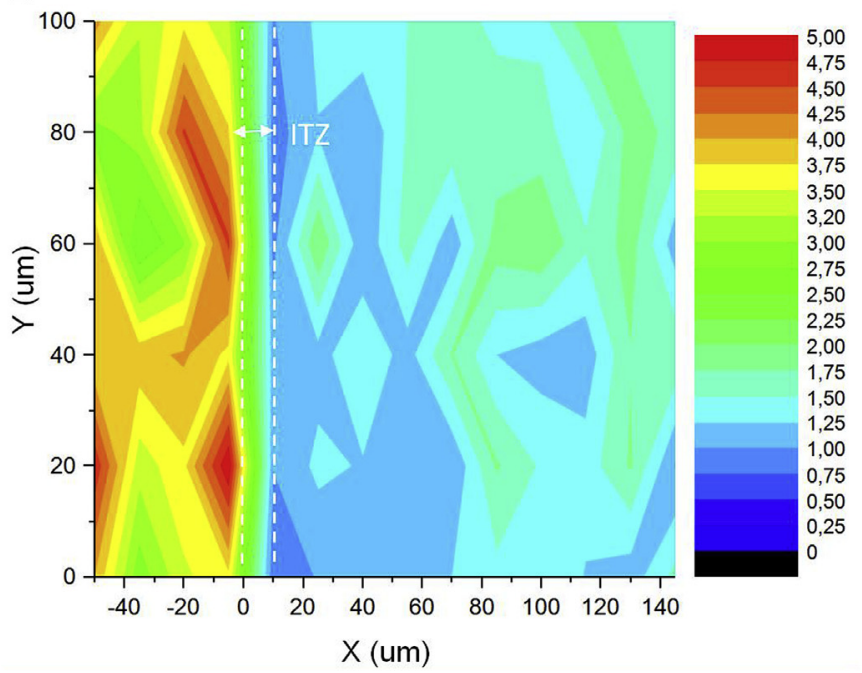

Fig. 17. Contour map of indentation hardness in concrete with $20 \%$ sugarcane industrial ashes (GPa); (A) W/B $=0.55$; (B) $\mathrm{W} / \mathrm{B}=0.35$.

showed a silico-alumina composition, followed by $\mathrm{Fe}_{2} \mathrm{O}_{3}$, which sum of the three oxides exceeded of $82 \%$ of total oxides. Mineralogicaly, the SCIA has amorphous phases and crystalline phases formed by quartz and hematites, probably due to a possible soil contamination during the collection and storage of wastes.

- According to fixed lime results, both pozzolan (SCIA and SF) showed high pozzollanic activity, but with different reaction rate. The biggest differences are found for the first 7 days of reaction. From this age, the differences between the values of fixed lime decrease, being similar to the silica fume at 90 days of reaction.

- Nanoindentation analyses indicated that the ITZ thickness varied significantly with the water/binder relation used for the reference concrete (approximately 25 and $85 \mu \mathrm{m}$ for $\mathrm{W} / \mathrm{B}=0.35$ and 0.55 , respectively).

- The utilization of either silica fume or SCIA causes a similar and significant reduction in the matrix-aggregate ITZ thickness in comparison to the reference concrete. The inclusion of $20 \%$ of silica fume or SCIA (by cement weight) caused a reduction of $70 \%$ in the thickness of the matrix-aggregate ITZ, in relation to the reference concrete. 
- In the concretes with either silica fume or SCIA, besides the thickness reduction of the ITZ, there was an elevation of the values of the indentation modulus and hardness in the ITZ.

\section{Acknowledgement}

The authors would like to thank the FAPESP (Projects: 2012/ 51467-3, 2011/16842-5, 2010/16524-0 and 2009/17293-5) and to iLINK program between CSIC and FAPESP (Project 2013/50790-8, iLink0675-2013) for their financial support. The authors are also grateful to the Framework Agreement of Collaboration between IETcc/CSIC (Spain) and FZEA/USP (Brazil) (Ref: 2013040043) and to CNPq (project \#306386/2013-5).

\section{References}

[1] R. Bechara, A. Gomez, V. Saint-Antonin, J. Schweitzer, F. Maréchal, Methodology for the optimal design of an integrated first and second generation ethanol production plant combined with power cogeneration, Bioresour Technol. 214 (2016) 441-449.

[2] M. Frías, E. Villar, H. Savastano Jr., Brazilian sugarcane bagasse ashes from the cogeneration industry as active pozzolans for cement manufacture, Cem. Concr. Comp. 33 (2013) 490-496.

[3] K. Hofsetz, M.A. Silva, Brazilian sugarcane bagasse: energy and non-energy consumption, Biomass Bioenergy 46 (2012) 564-573.

[4] M.R.L.V. Leal, M.V. Galdos, F.V. Scarpare, J.E.A. Seabra, A. Walter, C.O.F. Oliveira, Sugarcane straw availability, quality, recovery and energy use: a literature review, Biomass Bioenergy 53 (2013) 11-19.

[5] G.A. Dantas, L.F.L. Legey, A. Mazzone, Energy from sugarcane bagasse in Brazil: an assessment of the productivity and cost of different technological routes, Renew. Sustain. Energy Rev. 21 (2013) 356-364.

[6] S.C. Pereira, L. Maehara, C.M.M. Machado, C.S. Farinas, 2 G ethanol from the whole sugarcane lignocellulosic biomass, Biotechnol. Biofuels 8 (2015) 44 .

[7] F.M.V. Oliveira, I.O. Pineiro, A.M. Souto-Maior, C. Martin, A.R. Gonçalves, G.J.M. Rocha, Industrial-scale steam explosion pretreatment of sugarcane straw for enzymatic hydrolysis of cellulose for production of second generation ethanol and value-added products, Bioresour. Technol. 130 (2013) $168-173$.

[8] NOVACANA. Recolhimento e armazenamento do palhiço (ou palha) para 2a geração do ethanol. Available: http://www.novacana.com/etanol/ recolhimento-armazenamento-palhico-segunda-geracao/[Accessed November 2015]

[9] J.C.B. Moraes, J.L. Akasaki, J.L.P. Melges, J. Monzo, M.V. Borrachero, L. Soriano, J. Paya, M.M. Tashima, Assessment of sugar cane straw ash (SCSA) as pozzolanic material in blended Portland cement: microstructural characterization of pastes and mechanical strength of mortars, Constr. Build. Mater 94 (2015 670-677.

[10] G.A. Calligaris, M.K.K.D. Franco, L.P. Aldrige, M.S. Rodrigues, A. Beraldo, F. Yokaichiya, Assessing the pozzolanic activity of cements with added sugar cane straw ash by synchrotron X-ray diffraction and Rietveld analysis, Constr. Build. Mater 98 (2015) 44-50.

[11] E.V. Morales, E. Villar-Cociña, M. Frias, S.F. Santos, H. Savastano Jr., Effects of calcining conditions on the microstructure of sugar cane waste ashes (SCWA): influence in the pozzolanic activation, Cem. Concr. Comp. 31 (2009) 22-28.

[12] A. Guzmán, C. Gutiérrez, V. Amigó, R. Mejía De Gutiérrez, S. Delvasto, Valoración puzolánica de la hoja de la caña de azúcar, Mater. Construcción 61 (2011) 213-225.

[13] G.C. Cordeiro, R.D. Toledo-Filho, LM. Tavares, E.M.R Fairbairn, Ultrafine grinding of sugarcane bagasse ash for applications as pozzolanic admixtire in concrete, Cem. Concr. Res. 39 (2009) 110-115.

[14] M.S. Rodrigues, A.L. Beraldo, H. Savastano Jr., S.F. Santos, Sugarcane straw ash as a mineral addition in fibercement, Rev. Bras. Eng. Agrícola Ambient. 17 (2013) 1347-1354 (in portuguese).

[15] S.K. Antiohos, V.G. Papadakis, E. Chaniotakis, S. Tsimas, Improving the performance of ternary blended cements by mixing different types of fly ashes, Cem. Concr. Res. 37 (2007) 877-885.

[16] L. Bagel, Strength and pore structure of ternary blended cement mortars containing blast furnace slag and silica fume, Cem. Concr. Res. 28 (1998) 1011-1022.

[17] M.H. Shehata, M.D.A. Thomas, Use of ternary blends containing silica fume and fly ash to suppress expansion due to alkali-silica reaction in concrete Cem. Concr. Res. 32 (2002) 341-349.

[18] M.I. Khan, Isoresponses for strength, permeability and porosity of high performance mortar, Build. Environ. 38 (2003) 1051-1056.

[19] J. Bai, S. Wild, Investigation of the temperature change and heat evolution of mortar incorporating PFA and metakaolin. Cem. Concr. Comp. 24 (2002) 201-209.

[20] S. Goñi, M. Frías, R. Vigil, I. Vegas, Decalcification of activated paper sludge-fly ash Portland cement blended pastes in pure water, Cem. Concr. Comp. 40 (2013) 1-6.

[21] M. Frías, S. Goñi, R. García, R. Vigil, Seawater effect on durability of ternary cements, Synergy chloride sulphate ions. Compos. Part B Eng. 46 (2013) $173-178$.

[22] V.G. Jimenez-Quero, F.M. Leon-Martinez, P. Montes-Garcia, C. Gaona-Tiburcio, J.G. Chacón-Nava, Influence of sugarcane bagasse ash and fly ash on rheological behavior of cement pastes and mortars, Constr. Build. Mater 40 (2013) $691-701$.

[23] K.L. Scrivener, Backscattered electron imaging of cementitious microstructures: understanding and quantification, Cem. Concr. Comp. 26 (2004) 935-945.

[24] T.Y. Lo, H.Z. Cui, Effect of porous lightweight aggregate on strength of concrete, Mater. Lett. 58 (2004) 916-919.

[25] J.A. Rossignolo, Interfacial interactions in concretes with silica fume and SBR latex, Constr. Build. Mater 23 (2009) 817-821.

[26] S. Erdem, A.R. Dawson, N.H. Thom, Influence of the micro- and nanoscale local mechanical properties of the interfacial transition zone on impact behavior of concrete made with different aggregates, Cem. Concr. Res. 42 (2012) $447-458$.

[27] P. Duan, Z. Shui, W. Chen, C. Shen, Effects of metakaolin, silica fume and slag on pore structure, interfacial transition zone and compressive strength of concrete, Constr. Build. Mater 44 (2013) 1-6.

[28] F. Sanches, K. Sobolev, Nanotechnology in concrete - a review, Constr. Build. Mater 24 (2010) 2060-2071.

[29] W. Li, J. Xiao, Z. Sun, S. Kawashima, S.P. Shah, Interfacial transition zones in recycled aggregate concrete with different mixing approaches, Constr. Build. Mater 35 (2012) 1045-1055.

[30] J. Xiao, W. Li, Z. Sun, D.A. Lange, S.P. Shah, Properties of interfacial transition zones in recycled aggregate concrete tested by nanoindentation, Cem. Concr. Comp. 37 (2013) 276-292.

[31] W.R.L. Silva, J. Nemecek, P. Štemberk, Application of multiscale elastic homogenization based on nanoindentation for high performance concrete, Adv. Eng. Soft 62 (2013) 109-118.

[32] C. Hu, Z. Li, Micromechanical investigation of Portland cement paste, Constr. Build. Mater 71 (2014) 44-52.

[33] C. Medina, W. Zhub, T. Howindb, M.I.S. Rojas, M. Frías, Influence of interfacial transition zone on engineering properties of the concrete manufactured with recycled ceramic aggregate, Jour Civ. Eng. Manag. 21 (2015).

[34] ABNT NBR 5733, Associação Brasileira de Normas Técnicas, High. early strength Portland Cem. 5p (1991).

[35] M. Frias, H. Savastano Jr., M.I. Sanches De Rojas, S. Santos, Characterization and properties of blended cement matrices containing activated bamboo leaf wastes, Cem. Concr. Comp. 34 (2012) 1019-1023.

[36] EN 196-5, Methods of testing cements, Part 5 Pozzolanicity test pozzolanic Cem. (2011)

[37] A.R. Sakulich, V.C. Li, Nanoscale characterization of engineerd cementitios composites (ECCs), Cem. Concr. Res. 41 (2011) 169-175.

[38] P. Mondal, Nanoscale characterization of cementitious materials, ACI Mater. J. 105 (2008) 174-179.

[39] X.H. Wang, S. Jacobsen, J.Y. He, Z.L. Zhang, S.F. Lee, H.L. Lein, Application of nanoindentation testing to study of the interfacial transition zone in steel fiber reinforced mortar, Cem. Concr. Res. 39 (2009) 701-715.

[40] P. Mondal, Nanomechanical Properties of Cementitius Materials [Doctoral thesis], Northwestern University, USA, 2008.

[41] Z.H. He, C.X. Qian, Y. Zhang, F. Zhao, Y.G. Hu, Nanoindentation characteristics of cement with different mineral admixtures, Sci. China Tech. 56 (2013) 1119-1123.

[42] C. Hu, Z.J. Li, Y.Y. Gao, Y.G. Han, Y.M. Zhang, Investigation on microstructures of cementitious composites incorporating slag, Adv. Cem. Res. 26 (2014) $222-232$.

[43] W.C. Oliver, G.M. Pharr, An improved technique for determining hardness and elastic modulus using load and displacement sensing indentation experiments, Jour Mat. Res. 7 (1992) 1564-1583.

[44] ASTM, Standard Specification for Coal Fly Ash and Raw or Calcined Natural Pozzolan for Use in Concrete, 2012.

[45] EN 197-1, Composition, Specifications and Conformity Criteria for Common Cements, 2011.

[46] E. Villar-Cociña, M. Frías, J. Hernández-Ruiz, H. Savastano, Pozzolanic behaviour of a bagasse ash from the boiler of a cuban sugar Factory, Adv. Cem. Res. 25 (2013) 136-142.

[47] M. Frias, E. Villar-Cociña, E. Valencia-Morales, Characterisation of sugar cane straw waste as pozzolanic material for construction: calcining temperature and kinetic parameters, Waste Manag. 27 (2007) 533-538.

[48] E.Y. Nakanishi, M. Frías, S. Martínez-Ramírez, S.F. Santos, M.S. Rodrigues, O. Rodríguez, H. Savastano Jr., Characterization and properties of elephant grass ashes as supplementary cementing material in pozzolan/lime paste, Constr. Build. Mater 73 (2014) 391-398.

[49] M. Torsæter, J. Todorovic, A. Lavrov, Structure and debonding at cement-steel and cement-rock interfaces: effect of geometry and materials, Constr. Build. Mater 96 (2015) 164-171. 